\section{Romeu Beltrão e o Boletim do Instituto de Ciências Naturais}

\author{
Romeu Beltrão and the Bulletin of Natural Sciences
}

Elgion Lucio da Silva Loreto ' ; Karen Costa Soldi "

\section{RESUMO}

O Boletim do Instituto de Ciências Naturais da Universidade Federal de Santa Maria foi um periódico científico, publicado entre os anos 1962 e 1968. Representou um veículo para as pesquisas realizadas no Instituto de Ciências Naturais da então recémcriada Universidade Federal de Santa Maria. Os artigos publicados tratavam principalmente de fitogeografia e paleontologia da região. O mentor e principal contribuídor do periódico foi o prof. Romeu Beltrão, homem de múltiplos interesses. Foi médico, historiador, professor do ensino médio e superior, escritor, cronista, botânico, paleontólogo. O pioneirismo do "Boletim" é discutido dentro da evolução da pesquisa e pós-graduação na universidade em que ele surge. Também discutimos o potencial deste material para a abordar a Natureza da Ciência, e como o desenvolvimento científico está atrelado as condições sociais e históricas em que está inserido.

Palavras-chave: Historia natural; Natureza da Ciência; História da UFSM 
ABSTRACT

The Bulletin of the Institute of Natural Sciences of the Federal University of Santa Maria was a scientific journal, pub lished between 1962 and 1968. It represented a vehicle for research carried out at the Institute of Natural Sciences of the newly created Federal University of Santa Maria. The articles published addressed mainly the phytogeography and paleontology of the region. The main contributor and mentor of the journal was Prof. Romeu Beltrão, man of multiple interests. He was a doctor, historian, high school teacher, professor, writer, botanist, paleontologist. The pioneering "Bulletin" is discussed within the evolution of research and pos-graduate studies at the university in which it arises. We also discussed the potential of this material to address the Nature of Science, and how scientific development is tied to the social and historical conditions in which it is embedded.

Keywords: Natural history; Nature of Science; UFSM history.

\section{INTRODUÇÃO}

A formação universitária vai além das atividades didáticas das disciplinas curriculares. Em se tratando de formação nas áreas das Ciências é fundamental oportunizar a vivência do "fazer Ciência", possibilitando assim que o estudante possa apropriar-se de uma visão clara sobre a "Natureza da Ciência", compreendendo o que difere este conhecimento de outros, e das pseudociências (LEDERMAN, 2007). Natureza da Ciência é definido por Kampourakis (2016) como as características ligadas o conhecimento da Ciência e como este é produzido, como sua natureza experimental e exploratória (pode mudar com o tempo); sua construção, que é baseada empiricamente; e sua subjetividade, pois envolve inferência humana, imaginação e criatividade Quanto tratamos da Natureza da Ciência é fundamental a contextualização de que a Ciência é um empreendimento humano, emoldurado pelo contorno histórico-social em que é produzido. Assim, a história e a sociologia da Ciência deve fazer parte da formação acadêmica, principalmente nos cursos das áreas de formação cientifica. 
Os personagens das grandes revoluções científicas, as evidências e contextos históricos que marcaram as mudanças dos paradigmas científicos, como apontado por Kuhn (1997), devem fazer parte dos currículos dos cursos de formação científica. Mas uma boa estrutura universitária deve oportunizar, para além de atividades curriculares, possibilidades de iniciação científica e vivências de extensão universitária. Em uma universidade com "maturidade" acadêmica, as atividades de iniciação científica e extensão, se acompanhadas de uma visão histórica, em que o estudante possa sentir-se como parte de um processo, certamente será mais rica, permitindo apropriar-se de uma noção de Natureza da Ciência muito mais vivida e concreta. Para isto, os personagens e obras locais, principalmente os que foram os pioneiros na sua área de interesse, têm de ser apresentados. A história, os personagens e os feitos dos que criaram o curso, instituto ou centro de ensino da universidade onde o estudante está inserido deve estar presente na formação do aluno. Assim ele se sentirá parte de uma história, vivenciando de forma concreta a Natureza da Ciência.

Neste trabalho descrevemos uma obra singular, o Boletim do Instituto de Ciências Naturais, que está ligado ao surgimento do curso de História Natural da Universidade Federal de Santa Maria. São os primeiros relatos de pesquisa nas áreas de Biologia, Paleontologia e Geologia realizados na UFSM. Contextualizamos a obra e seu principal autor, o Prof. Romeu Beltrão, assim como o legado para a formação de naturalistas e professores na região central do Rio Grande do Sul e as relações com o desenvolvimento da pesquisa em Ciências Naturais na UFSM.

\section{O NATURALISTA ROMEU BELTRÃO ENTRE OUTROS “ROMEUS”}

Médico, historiador, professor do ensino médio e superior, escritor, cronista, botânico, paleontólogo. Tudo isto foi Romeu Beltrão, múltiplos Romeus (Figura1). Nasceu em Santa Maria no ano de 1913, estudou no Colégio Santa Maria e com 15 anos mudou se para Porto Alegre para cursar a Faculdade de Medicina de Porto 
Alegre. Após sua formatura retorna para sua cidade natal, em 1935, e em 1937 muda para São Pedro do Sul a fim de atuar como médico. Em 1938 retorna para Santa Maria onde inicia sua carreira como docente na Faculdade de Farmácia de Santa Maria, que será berço para a Universidade Federal de Santa Maria (UFSM). Sua atuação foi na área de Botânica Aplicada à Farmácia, onde desenvolveu um interesse por outras áreas da Ciência, como Paleontologia. Se torna diretor do instituto de Ciências Naturais da Universidade Federal de Santa Maria, onde desenvolveu projetos de pesquisa e de divulgação científica. Trocou correspondências e colaborações com pesquisadores do Brasil e exterior, principalmente referente a Botânica, Paleontologia e Geologia. O herbário da UFSM leva seu nome pela contribuição imensas que deixou.

Figura 1 - Prof. Romeu Beltrão

Figura 2 - Capa do primeiro volume do Boletim do Instituto de Ciências Naturais da UFSM

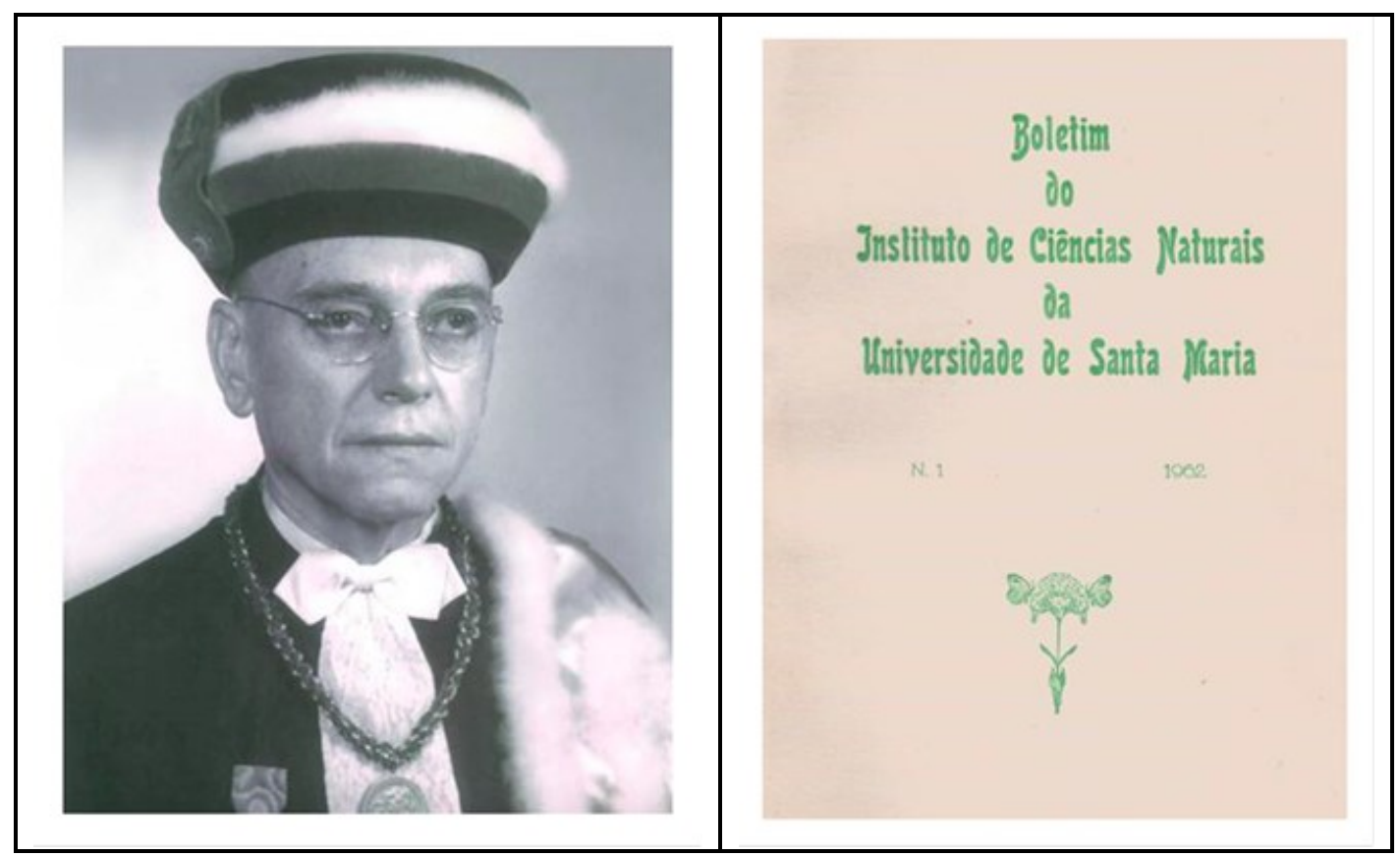

Em 1958 publicou um livro intitulado "Cronologia Histórica de Santa Maria e do extinto município de São Martinho 1787-1930". Nesta obra é o historiador que busca incansavelmente contar a história de sua cidade. A obra foi publicada mais duas vezes, em 1972 e sua última edição em 2013 (BELTRÃO 2013). Apesar de passado 
cinco décadas desde sua primeira publicação, o livro continua demonstrando a curiosidade de um médico- historiador sobre o local onde vivia, sobre a terra que havia em baixo de seus pés.

Por mais de uma década o cronista e escritor Romeu Beltrão escreveu assiduamente em jornais locais e regionais, em que abordava fatos históricos e pitorescos da sua cidade. Parte destas crônicas foram reunidas em um livro organizado por Paraense e Noal-Filho (2018).

Mas a produção acadêmica do naturalista Romeu Beltrão precisava de um foro apropriado para ser divulgado. Para isto criou o Boletim do Instituto de Ciências Naturais (Figura 2).

\section{O BOLETIM DO INSTITUTO DE CIÊNCIAS NATURAIS}

O Boletim do Instituto de Ciências Naturais da Universidade Federal de Santa Maria foi um periódico publicado entre os anos 1962 e 1968, pelo então Instituto de Ciências Naturais (ICN), da Universidade de Santa Maria, como a UFSM era chamada na época. Só no terceiro volume, na capa do Boletim, é referido o nome da Universidade como ela é conhecida atualmente. A frente deste periódico estava o prof. Romeu Beltrão, então diretor do ICN. O Boletim foi criado no mesmo ano da instalação do ICN, 1962, e tinha como objetivo divulgar os trabalhos científicos realizados no instituto, assim com noticiar as atividades do ICN (BELTRÃO, 1962a). O periódico tinha como o foco "às riquezas naturais da região que está localizada a Universidade Federal de Santa Maria, visando a despertar um crescente interêsse pelas nossas coisas" (BELTRÃO, 1965a).

O primeiro volume (1962) foi tratou preponderantemente de Botânica, tendo 3 artigos e o noticiário do ICN. Os autores, título e comentários sobre os artigos são disponibilizados na Tabela 1.

O segundo volume (1965) traz dois artigos escritos pelo prof. Beltrão, sobre paleontologia e Botânica. Traz ainda no noticiário o obituário do Pe. Balduino Rambo e a homenagem do ICN ao ilustre botânico. 
O terceiro volume (1968) é voltado a Geologia, e traz dois artigos. O primeiro é a tradução de um artigo escrito pelos geólogos alemães “Friedrich von Huene e Rudolf Stahlecker" com descrições geológicas da regiões de Santa Maria e São Pedro do Sul. O outro artigo, escrito pelo prof. Beltrão, teve como objetivo esclarecer dúvidas e termos a respeito do artigo escrito por Huene e Stakhlecker.

Versão eletrônica dos três volumes pode ser acessadas online: https://periodicos.ufsm.br/cienciaenatura/issue/archive (procurar nos anos correspondentes 1962-1968).

Tabela 1 - Artigos publicados no Boletim do Instituto de Ciências Naturais da UFSM

\begin{tabular}{|c|c|c|c|}
\hline Volume/Ano & Autor & Título do Artigo & Descrição \\
\hline $\begin{array}{c}1^{\circ} \text { volume - } \\
1962\end{array}$ & $\begin{array}{l}\text { Romeu } \\
\text { Beltrão }\end{array}$ & $\begin{array}{l}\text { Flórula fanerôgamica } \\
\text { do município de } \\
\text { Santa Maria, RS, } \\
\text { Brasil }\end{array}$ & $\begin{array}{l}\text { Contribuição à filogeografia do RS, traz um } \\
\text { levantamento de } 794 \text { espécies de plantas da } \\
\text { região de Santa Maria, com local de coleta, } \\
\text { coletor, mapa da região com os pontos de coleta, } \\
\text { e uma lista de nomes vulgares. }\end{array}$ \\
\hline $\begin{array}{c}1^{\circ} \text { volume - } \\
1962\end{array}$ & $\begin{array}{l}\text { Therezinha } \\
\text { Isaia Paviani }\end{array}$ & $\begin{array}{l}\text { Determinação da } \\
\text { viscosidade relativa } \\
\text { das folhas de } \\
\text { Hibiscus-rosa- } \\
\text { sinensis }\end{array}$ & $\begin{array}{l}\text { Descrição do procedimento utilizado para } \\
\text { determinar a viscosidade, como forma de estimar } \\
\text { a quantidade de mucilagem, considerado } \\
\text { componente medicinal de algumas plantas. }\end{array}$ \\
\hline $\begin{array}{c}1^{\circ} \text { volume - } \\
1962\end{array}$ & $\begin{array}{l}\text { Romeu } \\
\text { Beltrão }\end{array}$ & $\begin{array}{l}\text { Plantas, remédios e } \\
\text { superstições }\end{array}$ & $\begin{array}{c}\text { Conferência proferida na } 1^{a} \text { Jornada Farmacêutica } \\
\text { de Santa Maria, em que faz uma abordagem } \\
\text { crítica ao uso de plantas como elementos de } \\
\text { superstição }\end{array}$ \\
\hline
\end{tabular}

\begin{tabular}{|c|c|c|c|}
\hline $\begin{array}{c}1^{\circ} \text { volume - } \\
1962\end{array}$ & $\begin{array}{c}\text { Não } \\
\text { informado }\end{array}$ & $\begin{array}{c}\text { Noticiário: } \\
\text { Homenagem a } \\
\text { Botânico } \\
\text { Desaparecido }\end{array}$ & $\begin{array}{l}\text { Artigo em homenágem ao Pe. Balduino Rambo, } \\
\text { destacado botânico gaúcho, falecido em } 1961\end{array}$ \\
\hline $\begin{array}{l}2^{\circ} \text { volume - } \\
\quad 1965\end{array}$ & $\begin{array}{l}\text { Romeu } \\
\text { Beltrão }\end{array}$ & $\begin{array}{c}\text { Paleontologia de } \\
\text { Santa Maria e São } \\
\text { Pedro do Sul, RS, } \\
\text { Brasil }\end{array}$ & $\begin{array}{l}\text { Descrição histórica da paleontologia de Santa } \\
\text { Maria e São Pedro do Sul: os fósseis, localização } \\
\text { e estratigrafia dos depósitos fossilíferos. } \\
\text { Para o texto: vívida descrição do ambiente em } \\
\text { que viviam os sáurios do tríasico e como foi seu } \\
\text { desaparecimento. }\end{array}$ \\
\hline
\end{tabular}




\begin{tabular}{|c|c|c|c|}
\hline $\begin{array}{l}2^{\circ} \text { volume - } \\
\quad 1965\end{array}$ & $\begin{array}{l}\text { Romeu } \\
\text { Beltrão }\end{array}$ & $\begin{array}{l}\text { Flórula } \\
\text { Fanerogâmica do } \\
\text { município de Santa } \\
\text { Maria, RS, Brasil }\end{array}$ & $\begin{array}{c}\text { Continuação do levantamento da fitogeografia } \\
\text { publicado o } 1^{\circ} \text { volume, acrescentando mais } 280 \\
\text { espécies }\end{array}$ \\
\hline $\begin{array}{l}2^{\circ} \text { volume - } \\
1965\end{array}$ & $\begin{array}{l}\text { Não } \\
\text { informado }\end{array}$ & $\begin{array}{l}\text { Noticiário: } \\
\text { Clube de amigos da } \\
\text { Natureza }\end{array}$ & $\begin{array}{l}\text { Descreve a criação do Clube de amigos da } \\
\text { Natureza, iniciativa do Prof. Beltrão "congregando } \\
\text { todos quantos se interessam pelo estudo da } \\
\text { natureza" }\end{array}$ \\
\hline $\begin{array}{l}3^{\circ} \text { volume - } \\
1968\end{array}$ & $\begin{array}{l}\text { Friedrich von } \\
\text { Huene e } \\
\text { Rudolf } \\
\text { Stahlecker }\end{array}$ & $\begin{array}{l}\text { Observações } \\
\text { geológicas no Rio } \\
\text { Grande do Sul }\end{array}$ & $\begin{array}{l}\text { Uma das primeiras descrições geológicas da } \\
\text { regiões de Santa Maria e São Pedro do Sul }\end{array}$ \\
\hline $\begin{array}{l}3^{\circ} \text { volume - } \\
1968\end{array}$ & $\begin{array}{l}\text { Romeu } \\
\text { Beltrão }\end{array}$ & $\begin{array}{l}\text { Notas as } \\
\text { observações } \\
\text { geológicas no Rio } \\
\text { Grande do Sul }\end{array}$ & $\begin{array}{l}\text { Texto com esclarecimentos de dúvidas e termos a } \\
\text { respeito do artigo anterior (Huene e Stahlecker }\end{array}$ \\
\hline $\begin{array}{l}3^{\circ} \text { volume - } \\
1968\end{array}$ & $\begin{array}{l}\text { Não } \\
\text { informado }\end{array}$ & Noticiário & $\begin{array}{c}\text { Traz três notícias: a descoberta de um mini fóssil } \\
\text { na formação Santa Maria; novos achados } \\
\text { paleontológicos (crustáceos e plantas); sobre } \\
\text { Psaronios brasiliensis (planta fóssil) }\end{array}$ \\
\hline
\end{tabular}

\section{RACIONALIDADE E A NATUREZA DA CIÊNCIA}

Entre os artigos publicados no Boletim do Instituto de Ciências Naturais, um merece especial atenção pelo seu potencial como material didático para discutir a Natureza da Ciência. O artigo "Plantas, remédios e superstições" (BELTRÃO, 1962b) trata da racionalidade que deveria basear o uso de plantas medicinais, tendo como suporte o conhecimento de suas propriedades farmacológicas. No entanto, o autor traz inúmeros exemplos do "irracionalidade" no emprego de muitas plantas medicinais. Salienta ele que a superstição, e não a Ciência, é que norteia o uso de plantas medicinais por parte de várias pessoas, sendo isto, em geral, independente de escolaridade ou classe social. Mas cabe ressaltar também, que várias passagens do 
texto, em uma leitura com o olhar do Século XXI, pode parecer para alguns como racista e elitista. Por exemplo, a passagem: “Quando a preta velha Sia Rufina, pobre e ignorante, maloqueira do morro, sem Deus e sem palácio, coloca um ramo de arruda atrás da orêlha..." (BELTRÃO, 1962b), certamente causará desconforto a muitos leitores. Temos que contextualizar que somos, todos nós, imersos no espaço cultural do período que vivemos. Para Romeu Beltrão não seria diferente. O texto tem muito potencial para discutirmos a Natureza da Ciência, seja pela racionalidade que ele prega, seja para discutir o ambiente cultural em que se caracteriza a produção científica.

\section{O BOLETIM, SEU PIONEIRISMO E EXTEMPORANEIDADE}

O "Boletim" foi marcado por pioneirismo, principalmente se considerarmos que foi criado nos primeiros momentos da Universidade de Santa Maria, fundada em 1960. A UFSM foi a primeira universidade federal estabelecida em uma cidade do interior, e iniciava a interiorização do ensino superior público (GUTERRES e RAYS 2005). No seu começo, o primeiro desafio de uma universidade nova é organizar o ensino. A pesquisa e a extensão começam a se desenvolver e um momento subsequente. A pesquisa, ainda que não restrita a Pós-Graduação, está muito relacionada a esta, e na UFSM, os dois primeiros cursos de mestrado foram criados em 1970 e 1971, que foram em Educação e em Agronomia (GUTERRES e RAYS 2005; UFSM, 2013 ). No ano seguinte foram criadas periódicos ligados a estes cursos, sendo estes "Ciência Rural", e "Educação UFSM". Na Figura 3-A podemos ver o crescimento do número de revistas na UFSM e na Figura 3-B podemos ver o crescimento no número de cursos de Pós-Graduação na UFSM. Ao compararmos estes gráficos podemos ver que há uma correlação do aumento de número de cursos de PósGraduação e de periódicos na UFSM. O pioneirismo do Boletim fica evidente, pois este vem antes da Pós-Graduação e anterior aos demais periódicos. 
Os artigos publicados no Boletim são, para sua época, de alto nível. Cabe analisar porque o periódico não teve continuidade, extinguindo-se após três edições. Uma hipótese a ser levantada é que faltou uma comunidade de pesquisadores para alimentar as publicações. Outros periódicos criados na UFSM, uma década depois do Boletim, como Ciência Rural e Educação UFSM estão ativos até hoje, e se consolidaram como periódicos importantes em suas respectivas áreas. Possivelmente os cursos de Pós-Graduação ligados a eles deram a sustentação. Cursos de PósGraduação na área de Ciências Biológicas e Geociências, temas tratados no Boletim, só foram implantados 41 anos mais tarde, que foram os cursos de PG em Biodiversidade Animal e PG em Geografia \& Geociências, em 2003 (UFSM, 2013).

O Boletim foi a produção de um pesquisador só, Romeu Beltrão. Há dois artigos que não são de sua autoria. Um é uma produção independente da professora Therezinha Isaia Paviani do curso de Farmácia, e o outro dos naturalistas alemães Friedrich von Huene e Rudolf Stahlecker, em que o Prof. Beltrão se envolverá de forma direta, solicitando aos autores a permissão para tradução e na própria tradução desse artigo. Faltava uma comunidade acadêmica fazendo pesquisa em História Natural para serem divulgados no Boletim.

Mas estava claro, para o prof. Romeu Beltrão a importância dos periódicos científicos. Na introdução do volume 2 (BELTRÃO, 1965b) ele escreve: "No Brasil, as publicações cientificas nacionais são escassas e posta ao alcance de um número bastante reduzido de pessoas...e outro tanto se pode dizer das estrangeiras, cujo preço as vai tornando sempre mais um manjar de deuses para o leitor ou estudante brasileiro".

Como posto por PARAENSE e NOAL FILHO (2018) "Movido por preocupações nitidamente adiante de seu tempo e dotado de inteligência vívida e curiosa, Romeu Beltrão dirigiu seu olhar para múltiplas áreas do conhecimento...", A Botânica e a Paleontologia de "sua" Santa Maria estavam entre estas áreas, e o Boletim um instrumento para divulgar a pesquisa científica. Mas ele estava adiante do seu tempo. O Boletim foi uma obra extemporânea, ainda que maravilhosa. 
Figura 3 - A: Crescimento do número de periódicos na Universidade Federal de Santa Maria no período de sua criação (1960) até os dias atuais. B: Crescimento do número de cursos de Pós-Graduação na Universidade Federal de Santa Maria no período de sua criação (1960) até os dias atuais. (fonte: gráficos elaborados pelos autores a partir de dados coletados portal de periódicos da UFSM e Catálogo de cursos de PósGraduação UFSM)

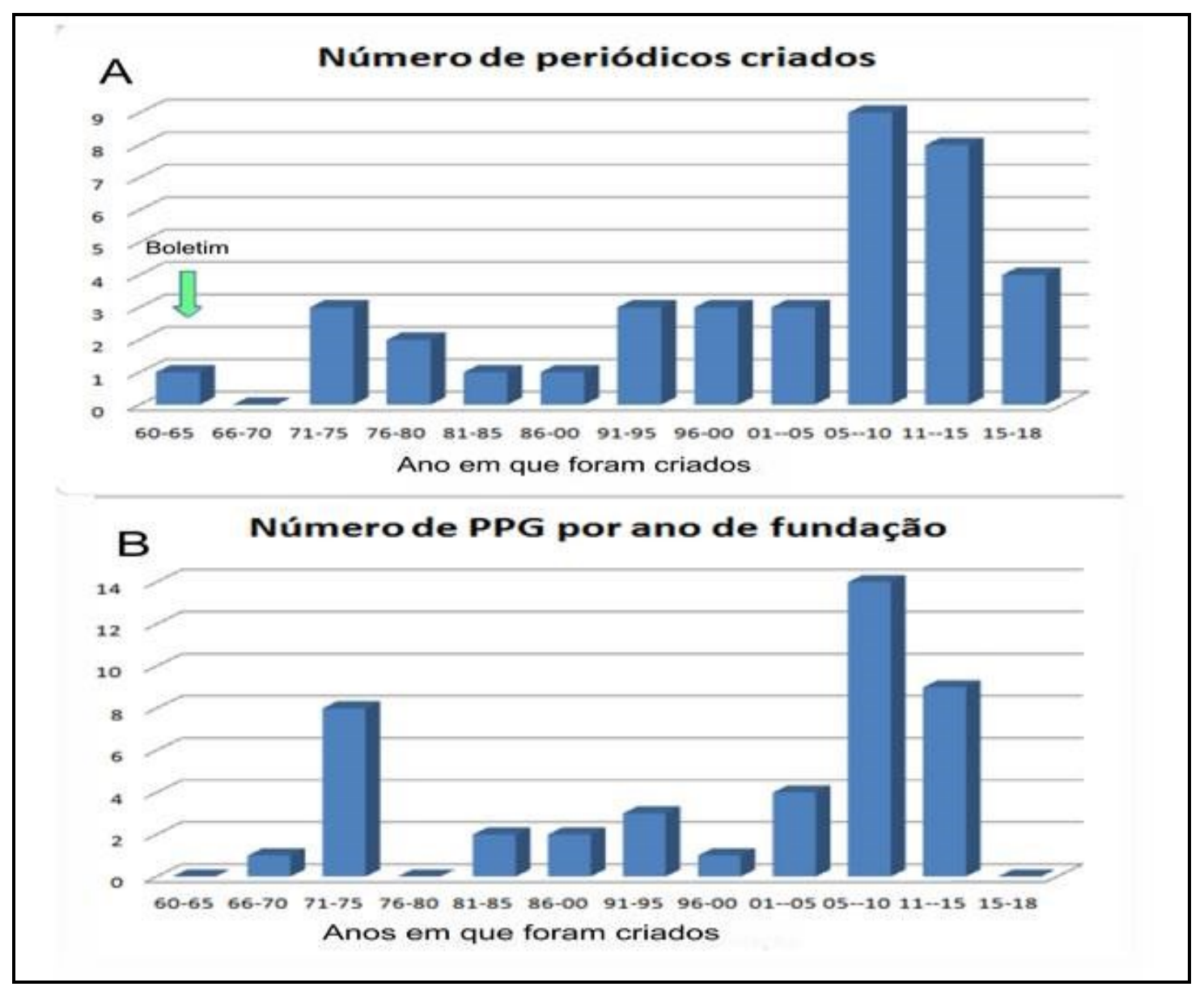

\section{UM LEGADO, UM EXEMPLO}

Será o "Boletim" uma extinção que não deixou descendentes, como os répteis triásicos de Santa Maria, cuja extinção foi tão vividamente descrita por Beltrão na pagina 105 do volume 2 do Boletim. Pensamos que não. Na introdução do volume 2 (1965), ao referir-se ao recém criado curso de História Natural da Faculdade de Filosofia da UFSM, está explícito que esperava-se que este curso “... não venha a formar professôres com as exclusivas preocupações de transmitir simplesmente aos alunos o que bem ou mal aprenderam e de correr ao guichê a cada fim de mês, mas também verdadeiros naturalistas, dedicados à ciência e a à pesquisa,..." 
O curso de História Natural seguiu seu curso e mais tarde torna-se Ciências Biológicas. Formou professores e pesquisadores. Beltrão deixa um exemplo e um legado que ajuda a explicar o que temos hoje nas Ciências Biológicas de Santa Maria e Região.

\section{CONCLUSÕES}

A obra de Romeu Beltrão em História Natural, e o Boletim do Instituto de Ciências Naturais corresponde a um material promissor para discussão da história e Natureza da Ciência, principalmente para atividades formativas de alunos do curso de Ciências Biológicas da UFSM, uma vez que corresponde a exemplo local, e tem potencial de ser contextualizado.

\section{REFERÊNCIAS}

BELTRÃO, ROMEU. Apresentação. 1962a Boletim do Instituto de Ciências Naturais da Universidade Federal de Santa Maria. 1:1.

BELTRÃO, ROMEU. Plantas, remédios e superstições. 1962b Boletim do Instituto de Ciências Naturais da Universidade Federal de Santa Maria. 1:73-87.

BELTRÃO, ROMEU. Apresentação. 1965a Boletim do Instituto de Ciências Naturais da Universidade Federal de Santa Maria. 2:1.

BELTRÃO, ROMEU. Introdução. 1965b Boletim do Instituto de Ciências Naturais da Universidade Federal de Santa Maria. 2:5-6.

BELTRÃO, ROMEU. Cronologia histórica de Santa Maria e do extinto município de São Martinho 1787 - 1930. 3ed. 2013. Santa Maria, Editora UFSM.

GUTERRES, CLOVIS R. J.; RAYS, OSWALDO. A. A Faculdade Interamericana de Educação na expansão da pós-graduação no Brasil. Revista Brasileira de Educação 2005; 30 (4): 81-94.

KAMPOURAKIS, KOSTAS. (The) Nature(s) of Science(s) and (the) Scientific Method(s). Sci \& Educ 2016. 25:1-2.

KUHN, THOMAS S. A estrutura das revoluções científicas 1997. 5. ed. São Paulo: Editora Perspectiva S.A, 
LEDERMAN, N. G. Nature of Science: past, present, and future, 831-880. In Abell, S.K. and Lederman, N.G. (Eds.), Handbook of Research on Science Education, 2007, Mahwah, NJ: Lawrence Erlbaum Associates.

PARAENSE, SILVIA C. L.; NOAL FILHO, VALTER. A. (Orgs). Santa Maria: o passado pitoresco, em prosa fluida! Romeu Beltrão. Santa Maria, Editora UFSM, 2018.

UFSM. Catálogo de cursos de Pós-Graduação UFSM 2013. Santa Maria, UFSM. 